\title{
Research
}

\section{Closing the Gap: Communicating to Change Gardening Practices in Support of Native Biodiversity in Urban Private Gardens}

\author{
$\underline{\text { Yolanda M. van Heezik }}^{1}, \underline{\text { Katharine J. M. Dickinson }}^{1}$, and Claire Freeman $^{1}$
}

\begin{abstract}
Private gardens collectively comprise the largest green space in most cities and the greatest potential for increasing the extent of wildlife-friendly and native-dominated habitat, improving the quality of ecosystem services, and providing opportunities for urban dwellers to reconnect with nature. Because attitudes and values driving landscape preferences in gardens are complex and often not conducive to biodiversity, and a gap exists between the possession of knowledge or values and the expression of pro-environmental behavior, facilitating change in gardening behavior is challenging. We attempted to improve knowledge and influence values, attitudes, and gardening behavior of 55 householders in favor of native biodiversity and environmentally friendly practices, through a two-way communication process, or interactive dialog, during a process of biodiversity documentation of their gardens. Informative feedback on their garden with a normative component was also provided. Despite being well educated and knowledgeable about common species at the start of the study, an increase in knowledge and shift in attitude was detected in $64 \%$ of householders: $40 \%$ reported a greater understanding of wildlife, and $26 \%$ made changes in their gardens, $13 \%$ to support native biodiversity. The normative component of our feedback information was of particular interest to $20 \%$ of householders. Because neighborhood norms influence gardening practices, changes adopted by a proportion of householders should be perpetuated across neighborhoods. The process of biodiversity assessment, dialog, and feedback was effective in improving knowledge of wildlife and native species, and stimulated a shift in attitude that resulted in native-friendly gardening practices. These changes were detected primarily through open self-report questions, rather than quantitative measures.
\end{abstract}

Key Words: attitude, behavior, communication, garden, gardening, native, urban, wildlife gardening

\section{INTRODUCTION}

Green spaces in urban areas can function as important havens for native plant and animal populations (Gregory and Baillie 1998, Mason 2000, Mörtberg and Wallentinus 2000, Smith et al. 2006a), and provide economically significant ecosystem services (Tratalos et al. 2007). Private gardens cover a large proportion of urban areas: between $22 \%$ and $27 \%$ of the total area of seven UK cities (Loram et al. 2007), and 36\% in a small New Zealand city (Mathieu et al. 2007). Gardens are very heterogeneous in their size and structure, varying widely in the provision of features that may promote biodiversity (Gaston et al. 2005, Smith et al. 2005). As a major component of green space, they have tremendous potential for supporting biodiversity, providing biodiversity benefits (Goddard et al. 2010), and improving connectivity of populations of native species that are currently largely limited to remnants (Doody et al. 2010).

Private ownership of gardens means that any city-wide improvement in gardens to support native biodiversity is largely dependent on the cumulative actions of large numbers of residents. Cultural and socioeconomic factors shape the motivations and attitudes behind gardening methods and landscape choices (Kinzig et al. 2005), and landscape aesthetics and lifestyle factors often take precedence over ecological concerns (Larson et al. 2009, Kiesling and Manning 2010). Any program aimed at effecting landscape-level change must acknowledge the diversity of attitudes arising from variable historical and cultural views (Larson et al. 2009, Zheng et al. 2011), and understand how responsive landowners may be to alter their activities to benefit biodiversity (Lepczyk et al. 2004). There has been very little research directed at identifying effective ways to motivate garden owners to change their gardening practices to support biodiversity, particularly native biodiversity. An important consideration is how to effectively communicate with people to raise awareness about gardens as ecosystems, and the potential role they play in supporting populations of native species, and ultimately change behavior in favor of gardening practices that not only support biodiversity in general, but native biodiversity specifically.

Communication with the intent of changing human behavior is difficult (Roggenbuck 1992, Orams 1997, Kollmuss and Agyeman 2002). There is a gap between possessing environmental knowledge and awareness, and demonstrating pro-environmental behavior, and many frameworks have been proposed to explain this gap (Kollmuss and Agyeman 2002). Attitudes, which are influenced by values and norms (perceived social pressures), determine behaviors, but actual behavior change is the final step in a transition from increasing knowledge, to attitude change, to the creation of intention to change behavior to actual behavior change (Orams 1997). Most effective, stable, and long-term behavior change is 
thought to be achieved if the central route concept can be applied, which requires that recipients think carefully about message content, integrate it into existing belief systems, and act accordingly (Roggenbuck 1992). An alternative approach proposed for the purposes of science communication is less of a one-way process and does not rely on high motivation and information-processing skills, but involves the creation of a two-way communication process or an interactive dialog, which is seen more as a collaborative exchange of information (Rennie et al. 2003, van der Sanden and Meijman 2008, Phipps 2010). Changing people's gardening behavior to support biodiversity, in particular native species, requires an understanding of the values that underlie attitudes, an acknowledgement of the norms that influence garden design and management (Nassauer et al. 2009), and a communication style that is effective in achieving long-term stable behavior change.

This study was part of a wider research project documenting biodiversity in a range of private gardens in New Zealand, and identifying what it is about gardens that make them valued and valuable (Freeman et al. 2012). As part of the process of evaluating peoples' relationships with their gardens, we wished to explore the potential for using a process of interactive dialog to stimulate behavior change toward more environmentally friendly gardening practices and greater support of native biodiversity. Urban gardens in the UK (Loram et al. 2008) and New Zealand (van Heezik et al., personal observation) are typically dominated by exotic plants. Although the proportion of exotic bird species in urban New Zealand (44\%) is very high (van Heezik et al. 2008), native birds are more abundant in areas of the city where native plants are more common (Day 1995, van Heezik et al. 2008). Although invertebrate abundance and diversity in the UK appears largely unrelated to native plant species richness, the structure and diversity of garden vegetation strongly influences invertebrate abundance and diversity (Smith et al. $2006 b, c)$. The choices people make in terms of what they plant, and how they structure and manage their garden, will influence the diversity and abundance of invertebrates and vertebrates.

We aimed to 1) evaluate knowledge, values, and attitudes concerning the environment, particularly native plants and animals, among a group of typical householders, and 2) determine whether communication in the form of an interactive dialog during the process of biodiversity documentation, including feedback with both informative and normative components, resulted in greater knowledge and a change in values, attitudes, and behaviors in favor of native biodiversity. We also explored a number of quantitative and qualitative approaches to evaluating changes in knowledge and attitudes of householders and report on their effectiveness.

\section{METHODS}

\section{Householders}

The study took place in Dunedin, New Zealand, which has a population 120 000. We recruited householders through advertisements in local newspapers. Voluntary recruitment was considered necessary as the required contact with householders over the course of a year included around 10 contact events. We avoided a strong bias toward those already interested in gardening, biodiversity, or wildlife, by careful advertising of the study, that is, "Gardens of all types, sizes, and condition are required." The subsequent selection was from a large number of volunteers from 55 gardens across 30 suburbs, to represent different garden types and sizes. All the householders were the owners of a property that included a fully detached house, usually surrounded on all sides by garden, except in a few instances where the house directly abutted the boundary. This is the most common type of urban property in New Zealand. The garden was defined as the total property area minus the area of the house and garage, but included paved or surfaced areas such as patios and decks.

Once recruited, one householder per property participated in two interviews; one at the start of the study, and a follow-up interview 10-12 months later. The goals of the study as presented to householders were to 1) document biodiversity in gardens; that is, to record all trees and shrubs and areal extent of lawns, hedges and beds, record birds and reptiles seen in the each garden, and sample for crawling invertebrates in lawns and beds, and 2) develop an understanding of the relationships people have with their gardens. We did not reveal that we were looking for changes in behavior as a consequence of the process of biodiversity documentation, because we wanted any changes to reflect a true change in values and attitudes, independent of perceived expectations of the study outcomes. We also did not advocate for native biodiversity, although we did distinguish between exotic and native species, provide information about planting native species and we made a comparative evaluation of the potential of each garden for supporting native birdlife as part of the normative feedback.

A single research assistant conducted all interviews and visited each property on a number of occasions to document plant species, landscape forms, vegetation structure, invertebrates, and birds. He allowed sufficient time to communicate with each householder, facilitating an exchange of information or interactive dialog with householders who informed him about issues concerning the way they managed their gardens, and he provided oral information if requested about the plants and animals he surveyed, situating them within the wider context of the ecosystem. The number of contact events with the research assistant was determined by the householder, but a minimum of eight visits were made to each property, with 
most properties visited about 10 times. Property values were obtained from the Dunedin City Council Search Rating Information database.

\section{Evaluating Knowledge, Values, and Attitudes}

We evaluated knowledge in both interviews by testing householders' ability to name and correctly classify as native, images of common native and exotic garden species that are regularly found in Dunedin gardens. These included 15 birds, 15 plants, and 15 nonavian fauna, including invertebrates, reptiles, and mammals. We asked householders whether they would prefer to plant native or exotic species.

Values were evaluated through a photothematic exercise. Householders accompanied the researcher around their garden at the beginning and end of the study, and photographed 10 features of their garden that they valued particularly. We grouped these into 16 themes: views, built structures, sentimental/cultural features, plant (mixed native/exotic), plant (exotic), plant (native), personal effort (where a large amount of effort had gone into a feature), geographic feature, food, fauna, domestic animals, access way, adjacent garden/ setting/feature, other natural feature, and other. We tested for a change in values by comparing the proportions of photos of native features.

We evaluated attitude quantitatively using Dunlap's revised New Ecological Paradigm (NEP), which is a Likert scale designed to reflect pro-environmental orientation, or "ecological worldview" (Dunlap et al. 2000), during both interviews. The NEP is the most widely used quantitative measure of environmental concern: changes in NEP scores have been used to examine the effects of specific experiences of environmental problems or the effectiveness of environmental education programs (Arcury and Christianson 1990, Rideout 2005, Manoli et al. 2007). A comparison of scores between interviews identified whether a shift toward a more pro-environmental attitude had occurred, given that this was the intention behind much of the communicative dialog. We also evaluated attitudes toward native species through two open questions: 1) do you like seeing native birds or are all birds equally important to you?; and 2) if you had a choice, would you prefer to plant natives or exotics?

\section{Information and Feedback}

We provided information on the results of vegetation and bird surveys across all gardens, and feedback specific to individual gardens, in the form of an attractive laminated A3 page. It included an identification guide with color images of the 10 birds, 10 plants, and 10 invertebrates that were most commonly seen across all gardens in the study, as well as websites providing information on planting natives, sustainable gardens, identification of birds, plants and beetles, and information on plant pests. An interesting fact specific to the householder's garden and in relation to other gardens in the study was provided; this was always positive. An example is as follows: "Although your garden has a great deal of lawn and not a lot of native species, your many flowering shrubs are an excellent source of food for insects, as well as native and non-native birds throughout the year." The feedback also included a normative component whereby the householder's garden was ranked in relation to others in the study as low, medium, or high with respect to the following: garden size, proportion vegetated, vegetation height, vegetation diversity, proportion of native vegetation, attractiveness to native birds, and proximity to a natural area. A summary of information about invertebrates collected in the following spring was also distributed as a newsletter. The information was intended to assist householders by directing them toward relevant sources of information if they were motivated to make changes. Some individuals are more influenced by norms than others, and the normative component was included to determine the proportion of these. We assessed the effectiveness of the feedback at promoting behavior change by asking householders whether they used the feedback information, and if so, how?

After the final interviews were completed, we invited all householders to a social gathering where the authors presented some preliminary results in an informal manner, and with the purpose of facilitating further dialog between researchers and householders as well as among householders. Approximately half of householders attended this event.

\section{Evaluating Changes in Knowledge, Values, Attitudes, and Behavior}

Using SPSS v. 19, Wilcoxon signed ranks tests to compare pre- and post-study scores: ID scores for plants, birds, and other fauna were combined. We tested for effects of level of education, sex of householders on attitude/knowledge using univariate analysis of variance with sex, and level of education as fixed factors. We coded level of education into three categories: most basic level of secondary school achievement or none (1); higher level of secondary school achievement and/ or trade certificate (2): and tertiary education (3). Post-hoc Tukey HSD tests were used to detect where differences lay.

In the final interview, we asked three open questions to identify any shifts in knowledge, attitude/values and behavior: whether involvement in the project had 1) influenced their understanding of wildlife, 2) influenced how they viewed their garden, and 3) made a difference to how they gardened. We also asked what motivated them to join the study. The full survey is available from the corresponding author.

\section{RESULTS}

\section{Characteristics of Householders and their Gardens}

Our sample of 55 gardens was representative of a wide range of urban property values and property sizes in Dunedin. 
Property sizes ranged between 0.018 ha and 0.282 ha (median $=0.061$; mean $=0.075 \pm 0.01 \mathrm{SE}$ ), with the vegetated area comprising between $15 \%$ and $95 \%$ (median $=62 \%$ ) of the total area. Property values ranged between NZD\$132 000 and $\$ 1125000$, (median $=\$ 250$ 000; mean $=\$ 312672 \pm 25,273$; average sales price for Dunedin $=\$ 273000$; http://www.immi gration.co.nz/life-in-new-zealand-for-migrants/new-zealandshousing-market.html). The level of education of householders also encompassed the entire range, but the proportion of householders with a post-school qualification was high at $62 \%$ c.f. $41 \%$ for the city (http://www.stats.govt.nz/census/2006ce nsushomepage) compared to those with a school qualification ( $29 \%$ c.f. $38 \%$ for the city) and with no qualification at all ( $10 \%$ c.f. $21 \%$ for the city). Women were over-represented in the study, with 39 female and 16 male householders, as were older people: 13 were aged over 65 (24\% c.f. $13 \%$ city-wide; (http://www.stats.govt.nz/census/2006censushomepage), 29 were aged 45-64 (53\% c.f. 22\% city-wide), and 13 aged 2544 ( $24 \%$ c.f. $24 \%$ city-wide). Most households ( $n=41,75 \%$ c. f. $44 \%$ city-wide) were couples without children or with grown children who had left. The most frequently given reason for joining the study was a desire to support university research (45\% of householders). Other reasons were: thought it might be interesting $(40 \%)$, to learn more about urban gardens $(14.5 \%)$, because they had an interest in wildlife/biodiversity (7.2\%), to compare their gardens with others' (3.6\%), and other miscellaneous reasons (5.4\%). These add to more than $100 \%$ because some householders gave more than one reason.

Almost all gardens were comprised of at least two of three components: beds, lawns, and hedges. All but two gardens had lawns (mean $=41 \% \pm 34 \% \mathrm{SD}$ of vegetated area), 36 gardens had hedges (mean $=6 \% \pm 8 \%$ SD of vegetated area), and all gardens had beds (mean $=38 \% \pm 22 \%$ of vegetated area). Vegetable beds typically contained a number of vegetable plants and were present in 35 gardens, comprising on average $15.9 \% \pm 17.3 \%$ of the total bed area.

\section{Knowledge of, and Values and Attitudes Toward, Biodiversity}

Householders were able to name most common plants (mean=12.0, $\mathrm{SD}=2.3$ ) and fauna (mean=11.8, $\mathrm{SD}=2.26$ ), but fewer birds (mean=9.7, $\mathrm{SD}=2.89$ ). They were able to identify correctly whether most plants (mean=13.0, $\mathrm{SD}=2.57$ ) and birds (mean=11.9, $\mathrm{SD}=3.4$ ) were native, but fewer mammals, reptiles, and invertebrates (mean=9.8, $\mathrm{SD}=2.93$ ). Householders' ability to name species and recognize them as native did not vary with gender (name; $F_{1 / 54}=1.151, P=0.289$; native; $F_{1 / 54}=0.102, P=0.751$ ) or education (name; $F_{2 / 54}=0.052$, $P=0.949$; native; $F_{2 / 54}=1.388, P=0.259$ ).

The initial photothematic exercise indicated that the most popular single feature was an exotic shrub or tree (32\% of total photos), followed by food plants, which were invariably exotic (herbs, vegetable gardens, and fruit trees, $16 \%$ ), native plants (usually a tree, 16\%) and structures (play areas for children, glasshouse, compost bin, seating associated with relaxation, and a fence/gate, $14 \%$ ).

The mean initial NEP score was 56.8 ( $\mathrm{SD}=8.4$, range 38-73). NEP scores did not vary according to gender $\left(F_{1 / 52}=0.429\right.$, $P=0.516)$ or level of education $\left(F_{1 / 52}=0.342, P=0.712\right)$. In response to the two open questions evaluating attitudes to native species, 58\% ( $n=32)$ of householders reported that they preferred seeing native birds, with $42 \%(n=23)$ reporting no preference for natives over exotics. A preference for planting natives was reported by $40 \%(n=22)$ of householders, $24 \%$ $(n=13)$ preferred exotic species (for food production and/or flowers) and $36 \%(n=20)$ preferred a mix.

\section{Evidence for Changes in Knowledge, Values, Attitude, and Behavior}

Householders in the second interview scored higher when naming species $(P<0.001)$ and categorizing species as native or exotic $(P<0.001)$. There was no change in the frequency of photo scores of native features between the two interviews $(P=0.131)$. There was also no change in NEP scores $(P=0.678)$.

Qualitative responses to open-ended questions revealed a shift in values, attitude and understanding. Nearly two-thirds of householders $(65 \%, n=36)$ reported a difference in how they viewed their garden, $40 \%(n=22)$ in their understanding of their garden as an ecosystem and/or its wildlife, and $26 \%$ $(n=14)$ that their involvement in the study had made a difference to the way they gardened. Differences in understanding and attitude toward gardens were grouped into themes (Fig. 1) and indicate improved understanding and awareness of various taxa at the end of the study relative to the beginning, in particular with respect to invertebrates; $14.5 \%$ reported a greater understanding and $24 \%$ greater appreciation or awareness at the end of the study. Most of the 22 householders who reported an increased understanding of some aspect of their gardens at the end of the study also reported a greater appreciation and knowledge about wildlife, with three $(5.5 \%)$ reporting a better understanding of their garden as an ecosystem. Among the 14 that reported changing the way they gardened, seven had adopted practices that were environmentally friendly. These practices included composting, using fewer chemicals, or encouraging invertebrates either through applying mulch or no longer using pesticides, and leaving areas of rank growth. Four householders had planted more natives, particularly those known to provide resources for native birds. In one case, a householder had replaced lawn with native shrubs. One householder created refuge and basking habitat for skinks. Some individuals had adopted a combination of these. Four householders reported developing their vegetable gardens further or were spending more time gardening. 
Fig. 1. Frequency of garden householder responses to the questions below. $\dagger$

Has being involved in this project improved your understanding of wildlife?

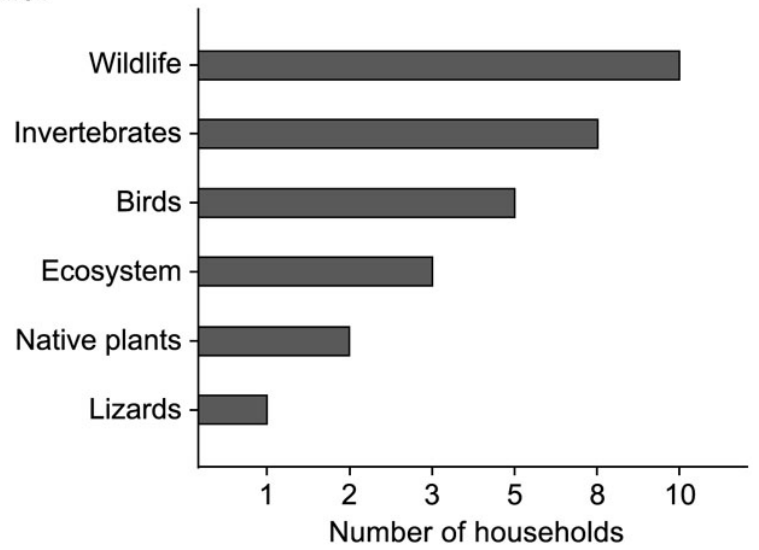

Has your involvement in the project changed how you view your garden?

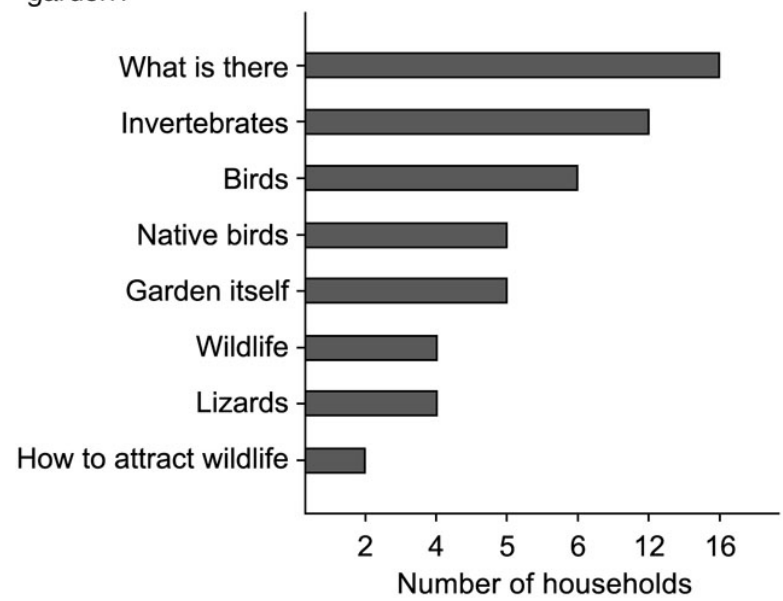

$\dagger$ Answers were grouped according to the following themes:"birds," "skinks," "invertebrates," "wildlife" (when no attempt was made to distinguish between animals), "ecosystem" (greater understanding of the garden as an ecosystem), "native plants" (greater understanding of role of native species [top] or changed view of native species [bottom]), "how to attract wildlife," and "what is there" (greater awareness and appreciation of the diversity of species in their garden).

\section{Value of Information and Feedback}

All householders reported that they had read the feedback information, and $29 \%(n=16)$ used it in at least one of the following ways: to inform planting, in most cases to choose suitable native species $(n=5)$; to identify plants and birds $(n=5)$; they showed it to family members/visitors $(n=3)$; their child used it for school projects $(n=1)$; to look at web links $(n=2)$; to learn how to feed birds $(n=2)$; and to create invertebrate habitat $(n=1)$. One person used it as teaching material in classes she gave on sustainable living, and another used it to pass on information to others. Both the written and normative components (garden comparison) were of particular interest to 11 , or $20 \%$, of the householders.

\section{DISCUSSION}

\section{Evaluation of Knowledge, Values, Attitudes, and Evidence of Change}

Strategies used to promote pro-environmental behaviors are often based on an assumption that problematic behaviors are caused by ignorance, requiring only the provision of information to rectify the situation (Roggenbuck 1992, Orams 1997). However, the gap between environmental knowledge and environmentally based behavior indicates the importance of the communication technique, as well as tailoring the message itself according to the knowledge, interest, and needs of the target audience (Ballantyne and Hughes 2006, Pelletier and Sharp 2008). This is the first study that we are aware of that integrates a biodiversity inventory with a process of reciprocal dialog between the researcher and the householder to facilitate meaningful changes in both attitude and behavior.

Although most garden householders were knowledgeable about species commonly encountered in the garden environment, they were less aware of the native/exotic status of most invertebrates and some birds. Doody et al. (2010) found even fewer householders able to identify plants as native, with scores improving with age: the bias toward older participants in our study may explain higher scores. Despite a high proportion (44\%) of exotic bird species in Dunedin, with three of the four most abundant species being exotic, (van Heezik et al. 2008), more than half of householders preferred seeing native birds and $76 \%$ reported they valued native plants or a native/exotic mix, indicating an encouraging level of awareness and appreciation of native biodiversity. Many people in New Zealand value native species as an expression of their national identity (Doody et al. 2010), and there is evidence of a growing appreciation of native plants in other countries (Town and Country Planning Association 2004, U. S. Environmental Protection Agency 2007). Despite the reported positive attitude toward natives, native plants only made up $17 \%$ of the total number of woody species, that is, shrubs and trees, found in gardens in the study (van Heezik et al., personal observation). Given that the overwhelming majority of nonwoody species in lawns and beds were exotic, natives comprised an even smaller proportion of the total. This is considerably less than the average of $45 \%$ of all plant species recorded for natives in UK gardens (Smith et al. 2006a), and illustrates the gap that occurs between recorded values and 
attitudes and actual behavior. Doody et al. (2010) also found a contradiction in that the native species identified by householders as valued (i.e., native), were also those they removed as weeds when they grew as self-dispersed seedlings in their gardens. They suggested that further education about native plants that meet individual householders' requirements is necessary to build on public interest and awareness.

Given the high level of knowledge found present at the beginning of the study, there was limited scope for large changes in knowledge or attitude; however, $40 \%$ reported an improved understanding of species and processes found in their gardens, and nearly two-thirds reported a greater awareness and appreciation of different facets of their gardens. Whereas some reported an increased awareness of birds and native plants, most were impressed by the abundance, diversity, and ecological role of invertebrates. Some householders learned to recognize birds by call and one started a bird list. Interest by homeowners in adopting ecologically sustainable gardening practices was also noted by Kiesling and Manning (2010), and Ryan and Grese (2005) reported that as many as $70 \%$ of people who gained knowledge through volunteering activities were more likely to plant natives and create wildlife habitat.

Attitudes may influence behavior, but behaviors do not always conform to attitudes, as they are influenced by a number of factors: normative constraints and expectations, personality, and the manner in which attitudes are formed (reviewed in Vincent and Fazio 1992). The complexity of factors influencing behavior and the short time frame of only one year lead us to expect very little behavior change; however, 26\% of householders reported that taking part in the study had provided them with the knowledge and stimulus to change some aspect of their garden, from creating refuges for skinks, to no longer killing insects, allowing weeds to grow, and, in one outstanding case, converting lawn to diverse native plants. Changes not associated with native biodiversity mainly involved food production. People selectively filter and restructure scientific information into a form they find personally meaningful and useful (Layton et al. 1993), and these people used the information they gained through contact with the researcher to change other facets of their gardens.

Because householders were self-selected, there were a disproportionate number of older, well-educated women participating in the study, although the gardens themselves were representative of the range in size and kinds of gardens across the city. It is possible that older, well-educated women that have a long experience with gardening may be more receptive to altering their gardening practices; however, the most frequent reason cited for joining the study was to support university research, with only four householders joining because they had an interest in wildlife/biodiversity. In addition, among the householders who showed behavior change, there were equal proportions of males and females, people with no/minimal qualifications and with university degrees, and they were a range of ages, suggesting that the findings of the study are applicable to the population as a whole.

\section{Communicating the Message}

If attitude and, ultimately, behavior change is the goal, then the observed and inferred characteristics of the messenger, the way in which information is communicated, whether onesided or as a dialog, the characteristics of the people receiving and giving the message, as well as situational factors all influence the effectiveness of communication (Ajzen 1992). We sought to inform through dialog rather than presentation of a message, and we believe that this was a key factor behind the success of our study, since the householders who joined the study were not necessarily seeking to be informed. Techniques for effectively communicating scientific information to the public have moved from a traditional topdown approach to recognition that communication is a twoway process of dialog (Phipps 2010), involving a more equal contribution from both the scientist and the public (Rennie et al. 2003, van der Sanden and Meijman 2008). The process of dialog we used addressed many of the issues that influence the effectiveness of communication, in that it was tailored to individuals. The collection of biodiversity data, fed back to householders in a free-choice, self-motivated learning environment, facilitated behavior change.

The feedback was read by most and used by some to identify species, communicate what they had learned to others, and seek information about bird feeding or gardening practices. The normative component of the feedback, which involved ranking the householder's garden against others in the study, proved an effective communication tool for at least $20 \%$ of householders. The degree to which neighborhood norms for landscape appearance might influence householders is likely to vary between individuals (Fishbein and Manfredo 1992). It would be useful to determine the strength of influence of norms among New Zealanders. Kirkpatrick et al. (2009) suggested that in Australia, one cannot rely on a process of neighborhood diffusion to encourage particular front garden attributes.

\section{Detecting Attitude/Behavior Change}

The self-reported data strongly supported a change in attitude and behavior among some householders. Self-reported data have been criticized as being unreliable when people are asked to remember details, particularly embarrassing ones, or reveal information that may portray themselves as less socially acceptable. Although semistructured interviews with a combination of closed and open questions can be very timeconsuming to carry out, they provide the opportunity to gain in-depth insights, and permit the study of a wide range of behavior. Self-reported data were very useful in evaluating the impact of an educational program concerning HIV risk that 
used both quantitative and qualitative methods to assess changes in attitudes and behavior (Barker et al. 2004), and also the effectiveness of a camp program on knowledge, attitudes, and behavior toward wildlife and protection of the environment (Kruse and Card 2004). Biases resulting from recall and embarrassing personal details did not apply to our study. The researcher was careful to maintain a nonjudgmental attitude, even when confronted with views that he disagreed with.

The quantitative data identified an increase in knowledge, but no change in values or attitudes. The lack of any change in NEP scores in this study may reflect the predominance of questions that involve much broader issues that most people might consider irrelevant to their gardens. Kiesling and Manning (2010) found a strong relationship between the "environmental identity scale" (EID; Clayton 2003) and engagement in ecological gardening practices, suggesting the EID might be a more appropriate tool to predict attitudes in this context. The photothematic exercise also failed to show a change in how native species were valued, possibly because the features selected by householders reflected a wide range of garden functions. These included features such as being a place to relax, socialize, produce food, or connect with nature (Gross and Lane 2007, Kiesling and Manning 2010), as well as typical "cues to care" (Nassauer 1995).

\section{CONCLUSIONS}

The benefits of influencing householder attitudes to be more appreciative and supportive of native biodiversity can be realized at more than one level: greater and better connected expanses of native-dominated habitat may act as havens for animal populations that rely on native species, improved ecosystem services in terms of carbon sequestration, climate regulation, and biodiversity potential. In turn, these may result in improved opportunities for urban dwellers to experience nature in their own neighborhoods, which can contribute positively to physical and mental wellbeing (Holbrook 2001). Dunn (2006) argues that conservation may increasingly depend on the ability of people in cities to maintain a connection with nature, with future incentives for conservation depending increasingly on people's interactions with nature in an urban setting. Ideally, this connection should be based on an appreciation of native species.

Although the method we used to influence values, attitudes, and behavior of householders was time consuming, our biodiversity inventories had a dual role: we learned a lot about existing biodiversity in gardens, as well as constructively interacting with householders. There is potential to scale the method up to include a larger section of the population by reducing the amount of information collected about vegetation composition and structure, which was the most timeconsuming component. Bird counts and invertebrate sampling take little time, and, in the case of the latter, stimulated a high degree of interest. If sufficient householders can be influenced to modify their gardens, neighborhood norms should ensure that the behavior change is perpetuated. Establishing a dialog was effective in influencing attitudes and behavior among a diverse group of people who did not join the study with the motivation of seeking information, and introducing a normative component to feedback was a valuable motivator for a proportion of householders, but changes were best evaluated through open questions in an interview.

Responses to this article can be read online at: http://www.ecologyandsociety.org/voll7/iss 1/art34/ responses/

\section{Acknowledgments:}

We thank all those who gave their time to participate in this study. S. Porter was supported by a University of Otago Research Grant, T. Connolly provided illustrated material, $B$. Barratt advised on invertebrate trapping, and P. Seddon commented on the manuscript.

\section{LITERATURE CITED}

Ajzen, I. 1992. Persuasive communication theory in social psychology: a historical perspective. Pages 2-28 in M. J. Manfredo, editor. Influencing human behavior. Sagamore, Champaign, Illinois, USA.

Arcury, T. A., and E. H. Christianson. 1990. Environmental worldview in response to environmental problems: Kentucky 1984 and 1998 compared. Environmental Behaviour 22:387407. http://dx.doi.org/10.1177/0013916590223004

Ballantyne, R., and K. Hughes. 2006. Using front-end and formative evaluation to design and test persuasive bird feeding warning signs. Tourism Management 27:235-246. http://dx.d oi.org/10.1016/j.tourman.2004.09.005

Barker, G., M. Nascimento, M. Segundo, and J. Pulerwitz. 2004. Measuring attitude and behavior change in young men with qualitative methods. $15^{\text {th }}$ International Conference on AIDS and STIs in Africa. Dakar, Senegal.

Clayton, S. 2003. Environmental identity: a conceptual and an operational definition. Pages 45-66 in S. Clayton and S. Opotow, editors. Identity and the natural environment: the psychological significance of nature. MIT Press, Cambridge, Massachusetts, USA.

Day, T. D. 1995. Bird species composition and abundance in relation to native plants in urban gardens, Hamilton, New Zealand. Notornis 42:175-186.

Doody, B. J., J. J. Sullivan, C. D. Meurk, G. H. Stewart, and H. C. Perkins. 2010. Urban realities: the contribution of 
residential gardens to the conservation of urban forest remnants. Biodiversity and Conservation 19:1385-1400. http ://dx.doi.org/10.1007/s10531-009-9768-2

Dunlap, R. E., K. D. Van Liere, and R. E. Jones. 2000. Measuring endorsement of the new ecological paradigm: a revised NEP scale. Journal of Social Issues 56:425-442. http ://dx.doi.org/10.1111/0022-4537.00176

Dunn, R. R., M. C. Gavin, M. C. Sanchez, and J. Solomon. 2006. The pigeon paradox: dependence of global conservation on urban nature. Conservation Biology 20:1814-1816. http:// dx.doi.org/10.1111/j.1523-1739.2006.00533.x

Fishbein, M., and M. J. Manfredo. 1992. A theory of behaviour change. Pages 29-50 in M. J. Manfredo, editor. Influencing human behavior. Sagamore, Champaign, Illinois, USA. http:/ /dx.doi.org/10.1177/01632780122034966

Freeman C., K. J. Dickinson, S. Porter, and Y. van Heezik. 2012. My garden is an expression of me: exploring householders' relationships with their gardens. Journal of Environmental Psychology. http://dx.doi.org/10.1016/j.jenvp .2012 .01 .005

32(2):135-143.

Gaston, K. J., P. H. Warren, K. Thomspon, and R. M. Smith. 2005. Urban domestic gardens (IV): the extent of the resources and its associated features. Biodiversity and Conservation 14:3327-3349. http://dx.doi.org/10.1007/s10531-004-9513-9

Goddard, M. A., A. J. Dougill, and T. G. Benton. 2010. Scaling up from gardens: biodiversity conservation in urban environments. Trends in Ecology and Evolution 25(2):90-98. http://dx.doi.org/10.1016/j.tree.2009.07.016

Gregory, R. D., and S. R. Baillie. 1998. Large-scale habitat use of some declining British birds. Journal of Applied Ecology 35:785-799. http://dx.doi.org/10.1046/j.1365-2664.1 998.355349.x

Gross, H.,and N. Lane. 2007. Landscapes of the lifespan: exploring accounts of own gardens and gardening. Journal of Environmental Psychology 27:225-241. http://dx.doi.org/10. 1016/j.jenvp.2007.04.003

Holbrooke, A. 2009. The green we need. An investigation of green life and green spaces for urban-dwellers' physical, mental and social health. Nursery and Garden Industry, Australia and The Centre for the Study of Research Training and Impact (SORTI), University of Newcastle, Australia.

Kiesling, F. M., and C. M. Manning. 2010. How green is your thumb? Environmental gardening identity an ecological gardening practices. Journal of Environmental Psychology 30:315-327. http://dx.doi.org/10.1016/j.jenvp.2010.02.004
Kinzig, A. P., P. Warren, C. Martin, C. Hope, and M. Katti. 2005. The effects of human socioeconomic status and cultural characteristics on urban patterns of biodiversity. Ecology and Society 10(1):23 http://www.ecologyandsociety.org/vol10/iss1/ $\underline{\operatorname{art} 23 / .23}$

Kirkpatrick, J., G. Daniels, and A. Davison. 2009. An antipodean test of spatial contagion in front garden character. Landcape and Urban Planning 93:103-110. http://dx.doi.org /10.1016/j.landurbplan.2009.06.009

Kollmuss, A., and J. Agyeman. 2002. Mind the gap: why do people act environmentally and what are the barriers to proenvironmental behaviour? Environmental Education Research 8(3):239-260. http://dx.doi.org/10.1080/13504620220145401

Kruse, C. K., and J. A. Card. 2004. Effects of a conservation education camp program on campers' self-reported knowledge, attitude, and behavior. Journal of Environmental Education 35:33-45. http://dx.doi.org/10.3200/JOEE.35.4.33-45

Larson, K. L., D. Casagrande, S. L. Harlan, and S. T. Yabiku. 2009. Resident's yard choices and rationales in a desert city: social priorities, ecological impacts, and decision tradeoffs. Environmental Management 44:921-937. http://dx.doi.org/10 $.1007 / \mathrm{s} 00267-009-9353-1$

Layton, D., E. Jenkins, S. MacGill, and A. Davey. 1993. Inarticulate science? Perspectives on the public understanding of science and some implications for science education. Studies in Education Ltd., Nafferton, UK.

Lepczyk, C. A., A. G. Mertig, and J. Liu. 2004. Assessing landowner activities related to birds across rural—urban landscapes. Environmental Management 33(1):110-125. http ://dx.doi.org/10.1007/s00267-003-0036-Z

Loram, A., J. Tratalos, P. H. Warren, and K. J. Gaston. 2007. Urban domestic gardens (X): the extent and structure of the resource in five major cities. Landscape Ecology 22:601-615. http://dx.doi.org/10.1007/s10980-006-9051-9

Loram, A., K. Thompson, P. H. Warren, and K. J. Gaston. 2008. Urban domestic gardens (XII): the richness and composition of the flora in five UK cities. Journal of Vegetation Science 19: 31-330. http://dx.doi.org/10.3170/200 $\underline{\text { 8-8-18373 }}$

Manoli, C. C., B. Johnson, and R. E. Dunlap. 2007. Assessing children's environmental worldviews: modifying and validating the new ecological paradigm scale for use with children. Journal of Environmental Education 38:3-13. http:/ /dx.doi.org/10.3200/JOEE.38.4.3-13 
Mason, C. F. 2000. Thrushes now largely restricted to the built environment in eastern England. Diversity and Distributions 6:189-194. http://dx.doi.org/10.1046/j.1472-4642.2000.00084. $\underline{\mathrm{x}}$

Mathieu, R., C. Freeman, and J. Aryal. 2007. Mapping private gardens in urban areas using object-oriented techniques and very high resolution satellite imagery. Landscape and Urban Planning 81:179-192. http://dx.doi.org/10.1016/j.landurbpla $\underline{\text { n.2006.11.009 }}$

Mörtberg, U., and H. G. Wallentinus. 2000. Red-listed forest bird species in an urban environment - assessment of green space corridors. Landscape and Urban Planning 50:215-226. http://dx.doi.org/10.1016/S0169-2046(00)00090-6

Nassauer, J. 1995. Messy ecosystems, orderly frames. Landscape Journal 14:161-170.

Nassauer, J. I., Z. Wang, and E. Dayrell. 2009. What will the neighbours think? Cultural norms and ecological design. Landscape and Urban Planning 92:282-292. http://dx.doi.or $\mathrm{g} / 10.1016 / \mathrm{j}$. landurbplan.2009.05.010

Orams, M. B. 1997. The effectiveness of environmental education: can we turn tourists into "greenies"? Progress in Tourism and Hospitality Research 3:295-306. http://dx.doi.o rg/10.1002/(SICI)1099-1603(199712)3:4<295::AID-PTH85>3.3. $\mathrm{CO} ; 2-4$

Pelletier, L. G., and E. Sharp. 2008. Persuasive communication and pro-environmental behaviours: how message tailoring and message framing can improve the integration of behaviours through self-determined motivation. Canadian Psychology 49:210-217. http://dx.doi.org/10.1037/ $\underline{\mathrm{a} 0012755}$

Phipps, M. 2010. Research trends and findings from a decade (1997-2007) of research on informal science education and free-choice science learning. Visitor Studies 13:3-22. http://d x.doi.org/10.1080/10645571003618717

Rennie, L. J. 2003. The communication of science and technology: past, present and future agendas. International Journal of Science Education 25:759-773. http://dx.doi.org/1 $\underline{0.1080 / 09500690305020}$

Rideout, B. E. 2005. The effect of a brief environmental problems module on endorsement of the new ecological paradigm in college students. Journal of Environmental Education 37:3-11. http://dx.doi.org/10.3200/JOEE.37.1.3-12

Roggenbuck, J. W. 1992. Use of persuasion to reduce visitor impacts and visitor conflicts. Pages 149-208 in M. J. Manfredo, editor. Influencing human behavior. Sagamore, Champaign, Illinois, USA.

Ryan, R. L. and R.E. Grese. 2005. Urban volunteers and the environment: forest and prairie restoration. Pages 173-188 in
P. F. Barlett, editor. Urban place: reconnecting with the natural world. MIT Press, Cambridge, Massachusetts, USA.

Smith, R. M., K. J. Gaston, P. H. Warren, and K. Thompson. 2005. Urban domestic gardens (V): relationships between landcover composition, housing and landscape. Landscape Ecology 20:235-253. http://dx.doi.org/10.1007/s10980-004-3160-0

Smith, R. M., K. Thompson, J. G. Hodgson, P. H. Warren, and K. J. Gaston. 2006a. Urban domestic gardens (IX): composition and richness of the vascular plant flora, and the implications for native biodiversity. Biological Conservation 129:312-322. http://dx.doi.org/10.1016/j.biocon.2005.10.045

Smith, R. M., K. J. Gaston, P. H. Warren and K. Thompson. 2006b. Urban domestic gardens (VIII): environmental correlates of invertebrate abundance. Biodiversity and Conservation 15(8):2515-2545. http://dx.doi.org/10.1007/s10 531-005-2784-y

Smith, R. M., P. H. Warren, K. Thompson, and K. J. Gaston. 2006c. Urban domestic gardens (VI): environmental correlates of invertebrate species richness. Biodiversity and Conservation 15:2415-2438. http://dx.doi.org/10.1007/s1053 1-004-5014-0

Town and Country Planning Association. 2004. Biodiversity by design: a guide for sustainable cities. London, UK.

Tratalos, J., R. A. Fuller, P. H. Warren, R. G. Davies, and K. J. Gaston. 2007. Urban form, biodiversity potential and ecosystem services. Landscape and Urban Planning 83:308317. http://dx.doi.org/10.1016/j.landurbplan.2007.05.003

U.S. Environmental Protection Agency. 2007. Greenlandscaping: greenacres. Washington, D.C., USA.

Vincent, M. A., and R. H. Fazio. 1992. Attitude accessibility and its consequences for judgement and behaviour. Pages $51-$ 76 in M. J. Manfredo, editor. Influencing human behavior. Sagamore, Champaign, Illinois, USA.

van der Sanden, M. C. A., and F. J. Meijman. 2008. Dialogue guides awareness and understanding of science: an essay on different goals of dialogue leading to different science communication approaches. Public Understanding of Science 17:89-103. http://dx.doi.org/10.1177/0963662506067376

van Heezik, Y., A. Smyth, R. Mathieu. 2008. Diversity of native and exotic birds across an urban gradient in a New Zealand city. Landscape and Urban Planning 87:223-232. http://dx.doi.org/10.1016/j.landurbplan.2008.06.004

Zheng, B., Y. Zhang, and J. Chen. 2011. Preference to home landscape: wildness or neatness? Landscape and Urban Planning 99:1-8. 